\title{
Perancangan Video Instruksional Pembelajaran Silat untuk Persatuan Gerak Badan Bangau Putih
}

\author{
Ruby Chrissandy ${ }^{1}$, Kurnia Setiawan ${ }^{2}$ Ferdy Tanumihardjo ${ }^{3}$ \\ Universitas Tarumanagara \\ rubyc@fsrd.untar.ac.id, kurnias@fsrd.untar.ac.id,ferdyt@fsrd.untar.ac.id
}

\begin{abstract}
Persatuan Gerak Badan Bangau Putih sebagai mitra kegiatan Pengabdian Kepada Masyarakat Universitas Tarumanagara merupakan perguruan silat yang berdiri tahun 1952 di Bogor. Saat ini PGB Bangau Putih memiliki cabang luar negeri di Jerman, Spanyol, Canada, Perancis, dan Amerika Serikat. Pemberian materi ke cabang luar negeri melalui pelatih, perwakilan luar negeri yang latihan di Indonesia. Kondisi ini menjadi masalah karena ada keterbatasan waktu, jarak dan ruang sehingga mereka membutuhkan media video instruksional. Metode perancangan video instruksional mengikuti tahapan produksi sebagai berikut: Tahapan pra produksi: menyusun shot list, jadwal produksi, dan tim produksi. Tahapan produksi: pengambilan gambar video. Tahapan paska produksi: editing video, input judul, lowerthird, export movie. Tahapan distribusi: serah terima video ke pihak PGB. Video dalam bentuk digital dengan format .mp4, ukuran 1080x720. Materi jurus Ambilan untuk sabuk Biru Muda, Hijau Tua, Hijau Muda, Kuning Muda, Kuning Tua, Orange, Coklat Muda, Coklat Tua. Total ada 9 sabuk dan 18 jurus Ambilan. Setting pencahayaan dibuat flat atau kontrasnya rendah agar detail gerakan mudah dilihat. Pengambilan gambar dengan posisi eye level mengikuti cara pandang normal manusia dan posisi kamera statis. Kesimpulan dari proses pembuatan video instruksional pembelajaran silat dibutuh kerjasama tim, proses kerja yang sistematik, dan komunikasi yang baik.
\end{abstract}

Kata kunci: video instruksional pembelajaran silat, PBG Bangau Putih

\section{PENDAHULUAN}

Teknologi video yang dikembangkan sejak tahun 1930 dengan munculnya stasiun televisi, lalu lahirnya alat perekam kaset video (VTR) di tahun 1956, dan komputer yang berperan menjadi alat pengontrol, perekam, dan editing video (Foust. 2018) mempengaruhi proses produksi video. Populernya laman Youtube di tahun 2006 dengan puluhan ribu unggahan video setiap hari dan sekarang tahun 2019 penggunanya menembus angka miliar dari seluruh dunia (O'Neill. 2018) mengubah perilaku orang sedunia dalam mengkonsumsi materi video, hiburan, dan pendidikan. Ada banyak video dengan format pengajaran di Youtube, video ini disebut video penjelasan atau instruksional, bentuk video ini berupa esai visual dengan serangkaian langkah-langkah dan membuat audiens belajar sebuah topik (Childress, 2018). Pembelajaran berbasis teknologi informasi menjadi alternatif terutama berkembangnya kursus online di internet dan video menjadi salah satu media yang digunakan dalam pembelajaran online (Zhang et al. 2006). Persatuan Gerak Badan Bangau Putih sebagai mitra kegiatan Pengabdian Kepada Masyarakat Universitas Tarumanagara merupakan perguruan silat yang berdiri tahun 1952 di Bogor. Didirikan oleh (alm) Suhu Subur Rahardja dan sekarang dipimpin oleh Guru Besar Gunawan Rahardja. Saat ini PGB Bangau Putih memiliki cabang 
luar negeri di Jerman, Spanyol, Canada, Perancis, dan Amerika Serikat.

Pemberian materi ke cabang luar negeri melalui pelatih, perwakilan luar negeri yang latihan di Indonesia. Kondisi ini menjadi masalah karena ada keterbatasan waktu, jarak dan ruang sehingga mereka membutuhkan media video instruksional. Banyak cabang baik di dalam maupun di luar negeri, juga kebutuhan koordinasi yang baik dalam membagikan materi agar sesuai dengan standard yang sudah ditetapkan, waktu pemberian materi harus sinkron antar cabang, dan belum ada dokumentasi gerakan tingkat lanjut dalam bentuk video mendorong PGB Bangau Putih merencanakan membuat video instruksional silat.

Pembuatan video instruksional relatif mudah jika topik, ide sudah ditentukan sehingga teknis video bisa dirancang dengan baik. Menurut Childress dalam membuat video penjelasan, langkah pertama pemilihan topik perlu dibahas diawal, lalu mencari ide dalam merencanakan video sesuai jalur materi, pendalaman topik harus dalam agar dapat fakta-fakta penting, bisa ditambahkan saran bagi penonton, dan menentukan bentuk videonya apakah animasi atau video atau gabungan. Proses pembuatan video melalui tahapan pra produksi, produksi dan paska produksi. Video ini prioritas pada informasi gerakan yang didemonstrasikan oleh peraga.
Produksi video instruksional memerlukan kerjasama dua belah pihak antara mitra dengan tim produksi karena isi video harus sesuai dengan kebutuhan mitra. Jadi tahapan pra produksi menjadi penting, perencanaan produksi dapat dimulai dengan menyusun jadwal, anggaran, konsep video, kru, dan naskah. Dengan perencanaan produksi yang matang maka video yang dihasilkan akan baik dan sesuai dengan kebutuhan mitra.

Kebutuhan video instruksional akan diberikan solusi sebagai berikut:

1. Mempersiapkan kebutuhan produksi seperti menyusun shot list gerakan yang ada, menyiapkan jadwal produksi, mencari tempat untuk shooting, mempersiapkan kru dan peralatan shooting, dan briefing dengan talent/pelatih.

2. Produksi video dengan shooting gerakan ambilan.

3. Editing video dengan memasukkan title untuk keterangan gerakan.

4. Export file video sesuai dengan standard format video Youtube.

Luaran yang akan diberikan berupa video instruksional dengan format MP4 ukuran $1080 \times 720$ sesuai dengan standar dari Youtube, dengan durasi video disesuaikan dengan gerakan yang ada, dari diskusi dapat diestimasi durasi di bawah 5 menit. Untuk latar musik menjadi unsur opsional, yang penting ada title sebagai keterangan gerakan. 


\section{METODE}

Tahapan awal atau sebelum pelaksanaan program ini dimulai dari diskusi awal antara mitra dengan Fakultas Seni Rupa dan Desain.

a. Penyusunan konsep video

b. Pencarian referensi dan riset pada Youtube tentang video sejenis

c. Perancangan konten materi video

d. Penyusunan tim pelaksana

e. Pemilihan peraga

f. Finalisasi dan pengunggahan

Tahapan produksi video terdiri dari tiga tahap: praproduksi, produksi dan paskaproduksi, proses ini berurutan atau sesuai kronologis tetapi masing-masing tahapan membutuhkan keterampilan dan pengetahuan yang berbeda-beda (Musburger. 2009)

Video pembelajaran dibuat harus menarik, harus relevan dengan konten dan disajikan pada durasi yang lebih rinci daripada kelas kuliah, video dapat diputar ulang dan memungkinkan peserta untuk mengulangi penjelasan instruktur, pada waktu, lokasi, dan di suasana lingkungan tempat mereka berada (Brecht 2008: 82).

Menurut Brunner ada lima tipe video instruksional; microvideo, tutorial video, training video, screencast, presentation \& lecture capture. Saat dibutuhkan mendemonstrasikan proses teknikal untuk kelas online atau mengajarkan seorang nenek cara menggunakan email, video adalah cara yang baik untuk tugas ini (Brunner, n.d.). Riset kepada para pelajar yang sangat dekat dengan teknologi digital (digital savvy) menyukai media video sebagai pembelajaran online. Teknologi video streaming yang baik dapat menghantarkan kualitas video yang tinggi sangat disukai mereka (Chan. 2010). Ini menjadi salah satu pertimbangan untuk merancang video instruksional pembelajaran silat PGB Bangau Putih.

Proses pembuatan produksi video dilakukan di satu lokasi agar memudahkan produksi. Berdasarkan tips langkah-langkah membuat video penjelasan dari Childress, sebagai berikut: memilih topik yang baik, menetapkan garis besar ide, riset materinya, akhir video mendorong audiens untuk belajar, dan proses produksi bisa menggunakan video, animasi atau gabungannya (Childress, 2018), maka tim mencoba mengadaptasinya ke proyek video instruksional silat PGB Bangau Putih. Pemilihan topik disesuaikan dengan kebutuhan mitra, yaitu memperlihatkan 18 jurus Ambilan dari 9 sabuk. Tim melakukan riset terhadap beberapa contoh video instruksional yang sejenis dan mengambil kesimpulan jenis video yang cocok untuk proyek ini dan didiskusikan dengan mitra. 


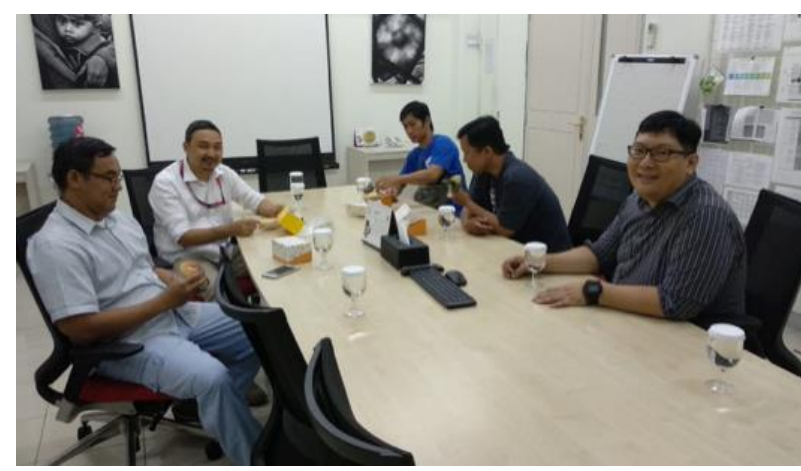

Gambar 2. Suasana diskusi tim tentang teknis produksi, 2019.

Video akan dibuat dengan satu atau dua orang peraga. Masing-masing gerakan akan diberi judul atau lowerthird sebagai keterangan nama jurus dan kategori sabuk. Pengambilan gambar dilakukan di studio dan menggunakan lampu LED khusus video dengan suhu warna $5600 \mathrm{~K}$.

Metode perancangan video instruksional mengikuti proses produksi sebagai berikut:

Tahapan pra produksi: menyusun shot list dari 18 jurus Ambilan, jadwal produksi, dan tim produksi.

Tahapan produksi: pengambilan gambar video Tahapan paska produksi: editing video, input judul, lowerthird, export movie.

Tahapan distribusi: serah terima video ke pihak PGB.

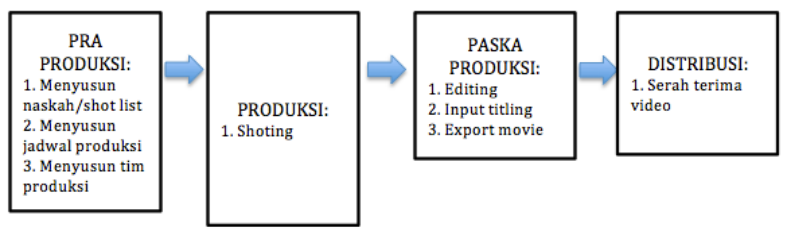

Gambar 1. Bagan metode pelaksanaan PKM pembuatan video instruksional, 2019.

\section{HASIL DAN PEMBAHASAN}

Pada PKM ini, tim akan membantu mitra dengan membuat video instruksional gerak silat tingkat lanjut. Video dalam bentuk digital dengan format mp4, ukuran $1080 \times 720$ untuk kebutuhan video di channel Youtube mitra. Materi gerakan disesuaikan dengan kebutuhan mitra, ambilan untuk sabuk Biru Muda, Hijau Tua, Hijau Muda, Kuning Muda, Kuning Tua, Jingga, Coklat Muda, Coklat Tua. Total ada 9 sabuk dan 18 jurus Ambilan. Setting pencahayaan dibuat flat atau kontrasnya rendah agar detail gerakan mudah dilihat. Pengambilan gambar dengan posisi eye level mengikuti cara pandang normal manusia dan posisi kamera statis. Demikian teknis video gerakan silat PGB Bangau Putih.

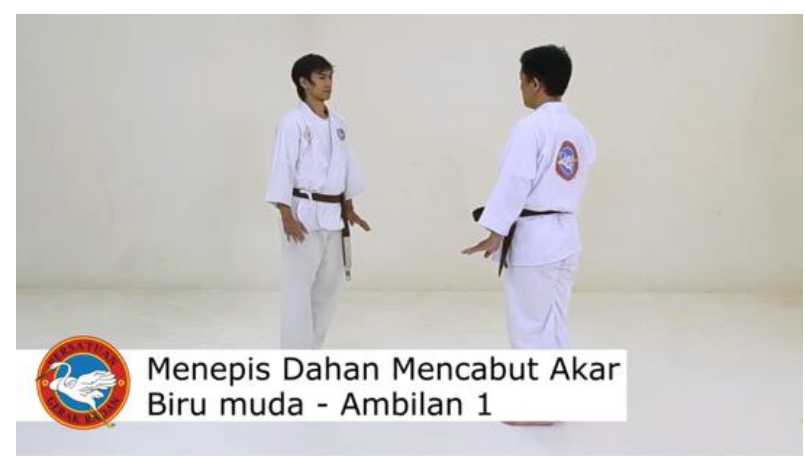

Gambar 3. Video dilengkapi dengan lowerthird untuk keterangan jurus Ambilan sesuai sabuknya, 2019.

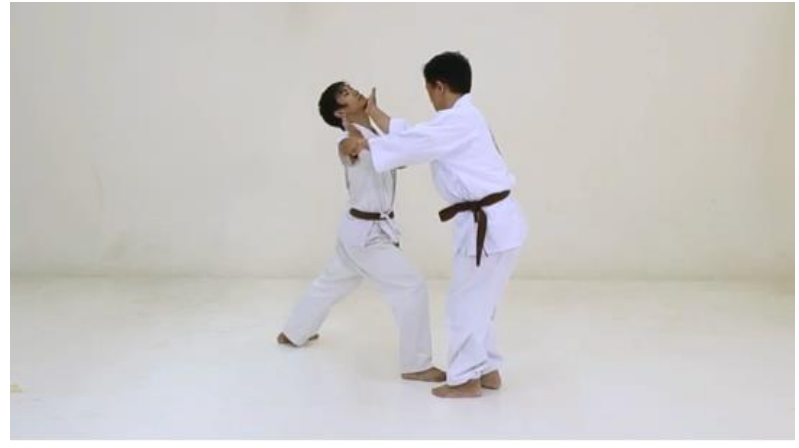

Gambar 4. Peragaan dua orang yang memperlihatkan cara menjatuhkan lawan, 2019. 


\section{SIMPULAN}

Perancangan video instruksional pembelajaran silat sudah sesuai dengan rencana dan hasil diskusi tim. Ruangan studio dengan ukuran sekitar $6 \times 8$ meter sangat memadai karena peraga harus bergerak saat memeragakan jurus. Penggunaan lensa sudut lebar $(28 \mathrm{~mm})$ diprioritaskan agar semua adegan dapat terekam, dengan komposisi orang full shot. Pencahayaan menggunakan tiga lampu led dan diposisikan sejajar dan dengan jarak sama agar hasilnya cahaya flat.

Kendala yang terjadi saat peraga melakukan kesalahan gerakan. Hal ini diantisipasi dengan pengambilan ulang sampai demonstrasi jurus sudah sempurna. Saat pengambilan gambar ada kru yang mencatat shot logging sehingga memudahkan editor memilih klip video yang baik. Jadi kesimpulan dari proses pembuatan video instruksional pembelajaran silat dibutuh kerjasama tim, proses kerja yang sistematik, dan komunikasi yang baik.

\section{UCAPAN TERIMA KASIH}

Penulis mengucap syukur kepada Tuhan YME dan berterima kasih kepada Gunawan Rahardja Guru Besar PGB Bangau Putih, Direktorat Penelitian dan Pengabdian kepada Masyarakat Universitas Tarumanagara, James Antonius selaku pelatih, Ko Fredy dan Yan
Fernando sebagai peraga atas dukungannya pada kegiatan PKM ini dan pihak-pihak yang tidak dapat disebutkan satu per satu.

\section{DAFTAR PUSTAKA}

Brecht, H. David, and Suzanne M. Ogilby. (2008). "Enabling a comprehensive teaching strategy: video lectures." Journal of Information Technology Education, vol. 7, p. IIP- 71(16). Gale Virtual Reference Library.

http://link.galegroup.com/apps/doc/A19 9685531/GPS?u=ktp03013\&sid=GPS\&xid =4 5b8efe. Accessed 25 Sep. 2018.

Brunner, D. (n.d.). 5 Types of Instructional Videos and When to Use Them. Retrieved from:

https://www.techsmith.com/blog/typesof-instructional- videos/

Chan, Yuen May. (2010). Video Instructions As Support For Beyond Classroom Learning, Social and Behavioral Sciences, vol.9, 2010, p.1313-1318. retrieved from https://doi.org/10.1016/j.sbspro.2010.12. 326.

Childress, Andrew. (2018). Bagaimana Membuat Video Penjelasan (alias Explainer). Retrieved from: https://photography.tutsplus.com/id/tut orials/how-to-make-an- explanationvideo--cms-27629 
Musburger, Robert B. Kindem, Gorham.

(2009). Introduction to media production:

The path to digital media production.

USA: Focal Press.

O'Neill, Siobhan. (2018). What is YouTube?.

Retrieved from:

https://www.digitalunite.com/technology

-guides/tv-video/youtube/what-youtube.

Zhang, Dongsong \& Zhou, Lina \& Briggs,

Robert \& Nunamaker, Jay. (2006).

Instructional Video in E-Learning:

Assessing The Impact of Interactive Video

On Learning Effectiveness. Information \&

Management 43.27.

10.1016/j.im.2005.01.004. 